\title{
COMPARATIVE STUDY OF PROCEDURAL SEDATION WITH ORAL TRICLOFOS AND TIVA IN CHILDREN FOR MRI SCANS
}

\author{
K. Chandra Sekhar1, D. Vijaya Kumar Rao ${ }^{2}$
}

${ }_{1}^{1}$ Associate Professor, Department of Anaesthesiology, Gitam Institute of Medical Sciences and Research, Visakhapatnam, A. P, India. 2Professor, Department of Anaesthesiology, Gitam Institute of Medical Sciences and Research, Visakhapatnam, A. P, India.

\begin{tabular}{l}
\hline ABSTRACT \\
BACKGROUND \\
Though triclofos is discouraged in children for fear of hepatotoxicity, ataxia and dizziness, one time administration in correct dosage \\
is helpful in children and often demanded and preferred to TIVA by anxious parents. Parents were explained about both techniques \\
and allowed to choose one method. Failed oral sedation cases were done with TIVA with good outcome.
\end{tabular}

\section{MATERIALS AND METHODS}

This was a non-randomised controlled trial. A total of 50 patients were non-randomly selected and was divided into two groups. 25 children in Group I were given oral triclofos and 25 children in Group II were given TIVA. All children are of ASA Group I and weighed between 3 and $10 \mathrm{kgs}$.

\section{RESULTS}

Oral triclofos worked well in $80 \%$ of children without side effects and TIVA worked well in $96 \%$ of child ren.

\section{CONCLUSION}

Though triclofos is discouraged for sedation, for its side effects, one time administration is safe in fit children with anxious parents and as a first line trial before resorting to intravenous line and more expensive TIVA.

\section{KEY WORDS}

TIVA, Triclofos.

HOW TO CITE THIS ARTICLE: Sekhar KC, Rao DVK. Comparative study of procedural sedation with oral triclofos and TIVA in children for MRI scans. J. Evolution Med. Dent. Sci. 2018;7(23):2797-2800, DOI: 10.14260/jemds/2018/631

\section{BACKGROUND}

Sedative decreases activity, moderates excitement and calms the patient. Hypnotic produces drowsiness and facilitates the onset and maintenance of sleep. Procedural sedation may be defined as the administration of sedative or dissociative agents or narcotic analgesic either alone or in combination to induce a state that allows the patient to tolerate unpleasant procedures, while maintaining cardio-respiratory function and preserving the protective airway reflexes. MRI is often advised for seizures, delayed mile stones, kernicterus, ADHD, mental retardation, autism, behavioural problems, neurosurgical planning and follow-up, hydrocephalus, microcephaly, minor head injuries, before cochlear implant surgery, congenital anomalies and weakness of limbs. Sedation with triclofos demands cooperation of child and multiple attendants, continuous counselling of queries by attendants about the safety of drugs and procedure. Often the child is precious, ill with financial burden. Parents are worried about outcome of sedation and the situation demands delicate handling by trained staff and anaesthetist. Many parents get fed up with failed sedation on day one and never accept syrup on the second day. TIVA is definitely advantageous to the anaesthetist, patient and parents.

'Financial or Other Competing Interest': None.

Submission 17-04-2018, Peer Review 21-05-2018,

Acceptance 28-05-2018, Published 04-06-2018.

Corresponding Author:

Dr. K. Chandra Sekhar,

Department of Anaesthesiology,

Gitam Institute of Medical Sciences and Research,

Rishikonda, Visakhapatnam, A. P, India.

E-mail: doctorkota123@gmail.com

DOI: $10.14260 /$ jemds $/ 2018 / 631$

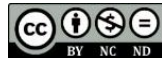

Onset of sedation is fast, recovery is immediate and hospital stay is less. No post-procedure restlessness or dizziness, subsequent procedures like EEG can be done with supplemental doses.

\section{Objective}

To study procedural sedation with oral triclofos and TIVA in children for MRI scans.

\section{MATERIALS AND METHODS}

This was a non-randomised controlled trial. Total 50 patients were non-randomly selected and was divided into two groups, was taken for convenience according to the drug used. Counselling was done to the parents about the syrup and TIVA and if the procedure could not be done with syrup the child was rescheduled for TIVA at later time. Children with IV line, admitted patients, post-surgery patients, children accompanied by ICU staff and consultant, willing parents, cases of failed oral sedation were done with TIVA.1,2,3

Triclofos was given at the dose of $75 \mathrm{mg} / \mathrm{kg}$ with sweetened vehicle like mango juice (frooti) or mixed with bottle milk.

\section{Inclusion Criteria}

Children with IV line, admitted patients, post-surgery patients, cases of failed oral sedation.

\section{Exclusion Criteria}

Respiratory infection, underweight, failure to thrive, dehydration, cardiac anomalies, hypothyroidism, laryngomalacia, tumours in the neck, change in voice, active seizures, ICU cases and prematures were excluded from study. 


\section{Methods of Administration}

Dropper, spoon, glass and feeding bottle were used as suggested by the parents for administering the drug. Syrup is sometimes administered in minute quantities repeatedly to prevent spitting and vomiting, as most of the children do not like unfamiliar taste. After thirty minutes if the child was not sedated, breast feeding or bottle feeding or solid food was allowed. Most of the patients slept within thirty minutes and some slept after feed.4,5,6,7 Failed sedation cases were posted for TIVA afterwards. Second dose was not given for fear of complications like ataxia, restlessness and dizziness. Parents are advised to stop giving the syrup, if the child is sleepy and not swallowing.

\section{Statistical Analysis}

Statistical analysis was performed using the SPSS 16.0 (Statistical Package for the Social Science for windows; Version 16.0, SPSS Inc., Chicago, USA). Results were analysed using student's t-test for parametric data and MannWhitney U-test for non-parametric data. Significance level was set at $\mathrm{P}<0.05$.

\section{RESULTS}

\section{Adverse Reactions}

Failed sedation, vomiting, spitting, refusal to take, delayed recovery, ataxia, rash, dizziness, respiratory depression and movement during procedure.

\begin{tabular}{|c|c|c|c|c|}
\hline Parameters & Oral Triclofos (25 Children) & TIVA (25 Children) & P \\
\hline Age (in years) & $3.68 \pm 0.55$ & $4.06 \pm 0.82$ & $5.62 \pm 0.46$ & 0.148 \\
\hline Sex (male/female) & $11 / 14$ & $11 / 14$ & $12 / 13$ & 0.001 \\
\hline Weight (kg) & $11.32 \pm 3.02$ & $12.96 \pm 2.64$ & $11.69 \pm 1.68$ & 0.068 \\
\hline Duration of Surgery (min) & $46.82 \pm 13.02$ & $48.91 \pm 11.31$ & $46.53 \pm 10.26$ & 0.092 \\
\hline Failure Rate & $8.06 \pm 2.62$ & $6.21 \pm 5.62$ & $4.68 \pm 4.61$ & 0.125 \\
\hline Post-Procedure Restlessness & $2.36 \pm 1.55$ & $6.06 \pm 1.82$ & $3.68 \pm 3.46$ & 0.132 \\
\hline Children Failure of Sedation & $1.68 \pm 2.41 \quad$ Table 1 & $2.46 \pm 3.82$ & $7.13 \pm 5.46$ & 0.458 \\
\hline \multicolumn{4}{|c|}{} \\
\hline
\end{tabular}

\section{Consent, Weight, Old Records, Fasting Protocol}

Pre-Procedure Fasting Protocol

Clear fluids 2 hours.

Breast milk 4 hours.

Formula milk 6 hours.

Cereal meal 6 hours.

Large meal 8 hours.

\section{Protocol Consent, Weight, Old Records, Fasting Observations}

- Parental acceptance.

- Sleep onset latency time.

- Failure of sedation.

- Movement during procedure.

\section{Conditions on Discharge}

- Vomiting.

- Ataxia.

- Restlessness.

- Residual sedation, dizziness.

- Involuntary movements.

- Ataxia.

\section{Acceptance of Medicine-Compliance Score}

1. Good- readily take.

2. Fair-accepts by persuasion.

3. Unwilling or spits out.

4. Refusal.

Counselling of parents about the procedure, IV line, risks, fasting protocols, duration of procedure, post-procedure fasting and mode of transport back home. Resuscitation tools are airways, ambu bag, central oxygen line, mucus sucker, laryngoscopes, ET tubes and emergency drugs.8,9

\section{Baby Separation at 30 Minutes}

1. Calm and sleepy.

2. Apprehensive, but withdrawn from surroundings.

3. Crying.

4. Agitated/ difficult to control.

\section{Sedation Scores}

1. Awake and oriented.

2. Drowsy.

3. Eyes closed, but rousable by command.

4. Eyes closed, but rousable by physical stimulation.

5. Eyes closed and unrousable.

\section{Group-II TIVA}

Counselling of parents about the procedure, IV line, risks, fasting protocols, duration of procedure, post-procedure fasting, mode of transport back home. Resuscitation tools are airways, ambu bag, central oxygen line, mucus sucker, suction, laryngoscopes, ET tubes and emergency drugs. TIVA with intravenous midazolam $(100 \mathrm{mcg} / \mathrm{kg})$, fentanyl $1 \mathrm{mcg} / \mathrm{kg})$ and propofol $(1 \mathrm{mg} / \mathrm{kg})$. Some children slept with midazolam alone, some with fentanyl and midazolam and some with the addition of propofol. Reason being the summative effect of drugs already receiving by the patient like phenobarbitone in fits and resistance is due to rapid metabolism by microsomal enzyme induction. Balanced anaesthesia is administration of minimal amounts of multiple neuronal depressants to summate the advantages of individual drug. On table monitoring pain on injection and involuntary movements with propofol, cough, hiccups secretions, apnoea, respiratory depression, fall in oxygen saturation, bradycardia and movement in the middle of the procedure.10,11,12 Extended sedation to complete further investigations for EEG, nerve conduction, BERA, CT, Ultrasound, contrast study, spectrography, detailed study by giving incremental doses. Other methods of sedation include ketamine, oral hydroxyzine, rectal thiopentone, oral midazolam and midazolam nasal spray. 


\begin{tabular}{|c|c|c|c|}
\hline Score & \begin{tabular}{|c|} 
Group 1 Oral \\
Triclofos $(\mathrm{n}=25)(\%)$ \\
\end{tabular} & $\begin{array}{c}\text { Group } 2 \text { TIVA } \\
(n=25)(\%)\end{array}$ & $\mathbf{P}$ \\
\hline 1 & 60 & 96 & \multirow{5}{*}{0.362} \\
\hline 2 & 20 & 4 & \\
\hline 3 & 20 & & \\
\hline 4 & 80 & & \\
\hline 5 & 20 & & \\
\hline \multicolumn{4}{|c|}{ Table 2} \\
\hline
\end{tabular}

Complications: TIVA drug interacts with drugs already in use, delayed sedation, sedation with small doses, pain on injection with propofol, cough, hiccups, laryngospasm, bronchospasm, wheeze, bradycardia, fall in oxygen saturation, jaw drop, respiratory depression, secretions and resistance to sedative drugs. Anticholinergic medication was avoided as bradycardia producing conditions like deep sedation, deep anaesthesia or painful procedure. Inhalational agents were not involved in the procedure. Child is observed for bradycardia with MRI compatible pulse oximeter. TIVA with intravenous midazolam (100 mcg/kg), fentanyl ( $1 \mathrm{mcg} / \mathrm{kg}$ ) and propofol $(1 \mathrm{mg} / \mathrm{kg})$. Discharge Criteria: Fully awake, crying, no respiratory depression, no restlessness. ${ }^{13}$ Transport back home by two wheeler is not advised for safety reasons.

\section{DISCUSSION}

Balanced anaesthesia is administration of minimal amounts of multiple neuronal depressants to summate the advantages of individual drug. Sub-anaesthetic doses of induction agents produces sleep with preservation of air way reflexes. This principle is used for procedural sedation in painless procedures. It is difficult to sedate the baby in cold and noisy MRI room and some wake up in the middle of the procedure. MRI is non-invasive, no risk of radiation, needs MRI compatible monitors and resuscitation equipment. Procedural sedation may be defined as the administration of sedative or dissociative agents or narcotic analgesics either alone or in combination, to induce a state that allows the patient to tolerate unpleasant procedures while maintaining cardiorespiratory function and preserving the protective airway reflexes. Anaesthesia outside operation theatre is also known as NORA (non-operating room anaesthesia) care/ MAC monitored anaesthesia care. Standard protocols, open communication with personnel and patient monitoring are essential regardless of location. Limitations unfamiliar limited space, limited access to patient, poor lighting, noisy and cold room and less skilled staff balancing the depth of sedation, preservation of airway reflexes are important managing the case. ${ }^{14}$ Metabolised to trichloroethanol may cause liver damage and should not be used for extended periods. Dose should not exceed $70-120 \mathrm{mg} / \mathrm{kg}$ at any time. ${ }^{15}$

TIVA is advantageous than oral triclofos in rapid onset of sedation, recovery is not delayed, no residual sedation. Child is more alert at discharge, early feeding, no post-procedure restlessness or dizziness. Ketamine is not advocated for day case procedures, for hoarseness of voice, increased secretions, nystagmus, delayed recovery, difficult to convince the attendants about side effects, difficult to bring back the child pre-procedure state of alertness in case of complications.
Comparison of Oral Triclofos and TIVA

\begin{tabular}{|c|c|c|}
\hline Cost & Cheap & Expensive \\
\hline Intravenous line & Not required & Required \\
\hline Failure rate & $20 \%$ & $4 \%$ \\
\hline $\begin{array}{c}\text { Post-procedure } \\
\text { restlessness }\end{array}$ & $4 \%$ & Nil \\
\hline Choice by & Parents & Consultants \\
\hline Sleep onset latency & 30 minutes & Immediate \\
\hline $\begin{array}{c}\text { Movement during } \\
\text { procedure }\end{array}$ & Scan abandoned & $\begin{array}{c}\text { Supplementary } \\
\text { doses given }\end{array}$ \\
\hline $\begin{array}{c}\text { Extended study } \\
\text { beyond scan }\end{array}$ & Not possible & $\begin{array}{c}\text { Possible by } \\
\text { incremental doses }\end{array}$ \\
\hline $\begin{array}{c}\text { Acceptance by } \\
\text { parents }\end{array}$ & Good & $\begin{array}{c}\text { Difficult to } \\
\text { convince }\end{array}$ \\
\hline $\begin{array}{c}\text { Post-procedure } \\
\text { restlessness }\end{array}$ & $4 \%$ & Nil \\
\hline Home readiness & Delayed & No delay \\
\hline Apnoea & Not common & Common \\
\hline Jaw drop & Not common & Common \\
\hline Bradycardia & Not common & Common \\
\hline \multicolumn{2}{|c|}{ Table 3 } \\
\hline
\end{tabular}

\section{CONCLUSION}

Though triclofos is discouraged for sedation for its side effects, one time administration is safe in fit children with anxious parents and as a first line trial before resorting to intravenous line and more expensive TIVA.

\section{REFERENCES}

[1] Beeby DG, Hughes J0. Behaviour of unsedated children in anesthetic room. Br J Anesth 1980;52(3):279-81.

[2] Jackson EA, Rebbette PS, Dezateux C, et al. The effect of triclofos sodium sedation on respiratory rate, oxygen saturation and heart rate in infants and young children. Pediatr Pulmonol 1991;10(1):40-5.

[3] Parameswari A, Maheedar G, Vakamudi M. Sedative and anxiolytic effects of midazolam and triclofos oral pre medication in children undergoing elective surgery: a comparison. Journal of Anaesth and Clinical Pharmacology 2010;26(3):340-4.

[4] Shabbir A, Bhatt SS, Hegde SK, et al. Comparison of oral midazolam and triclofos in conscious sedation in uncooperative children. J clinical Pediatr Dental 2011;36(2):189-96.

[5] Choudhary S, Jindal R, Girotra G, et al. Is midazolam superior to triclofos and hydroxygine as premedicant in children? J Anest Clinical Pharma 2014;30(1):53-8.

[6] Millichap JG. EEG evaluation of triclofos sodium sedation in children. Am J of Dis Child 1972;124(4):526-7.

[7] Alario AJ, Lewander WJ, Dennehy P, et al. The Relationship between and $\mathrm{O}^{2}$ saturation and the clinical assessment of acutely wheezing infants and children. Pediatr Emergency Care 1995;11(6)331-9.

[8] Dalal PG, Murray D, Cox T, et al. Sedation and anesthesia protocols used for MRI studies in infants: provider and pharmacologic considerations. Anesth Analgesia 2006;103(4):863-8.

[9] Serafini G, Zadra N. Anesthesia for MRI in pediatric patient. Curr Opin Anesth 2008;21(4):499-503. 
[10] Metzner J, Domino KB. Risks of anesthesia or sedation outside operating room: role of the anesthesia care provider. Curr Opinion Anesthesia 2010;23(4):523-31.

[11] Chidambaram V, Costandi A, D'Mello A. Propofol a review of its role in pediatric anesthesia and sedation. CNS Drugs 2015;29(7):543-63.

[12] Steur RJ, Perez RS, De Lange JJ. Dosage scheme for propofol in children under 3 years of age. Paediatr Anaesth 2004;14(6):462-7.
[13] Bloomfield EL, Masaryk TJ, Caplin A, et al. Intravenous sedation for MR imaging of the brain and spine in children: pentobarbital versus propofol. Radiology 1993;186(1):93-7.

[14] Vangerven M, Van Hemelrijck J, Wouters P, et al. Light anaesthesia with propofol for paediatric MRI. Anaesthesia 1992;47(8):706-7.

[15] Lefever EB, Potter PS, Seeley NR. Propofol sedation for pediatric MRI (Letter). Anesth Analg 1993;76(4):91920. 